\title{
Observações acerca da reestruturação urbana na Zona Portuária do Rio de Janeiro
}

Remarks on urban restructuring in Rio de Janeiro's dockland

Observaciones sobre la reestructuración urbana en la zona portuaria de Río de Janeiro

Remarques sur la restructuration urbaine de la zone portuaire à Rio de Janeiro

\section{Gabriel Silva de Araujo Teixeira}

\section{(Q) OpenEdition}

\section{Journals}

Edição electrónica

URL: http://journals.openedition.org/espacoeconomia/1323

DOI: $10.4000 /$ espacoeconomia.1323

ISSN: 2317-7837

Editora

Núcleo de Pesquisa Espaço \& Economia

Refêrencia eletrónica

Gabriel Silva de Araujo Teixeira, «Observações acerca da reestruturação urbana na Zona Portuária do Rio de Janeiro », Espaço e Economia [Online], 5 | 2014, posto online no dia 29 dezembro 2014, consultado o 13 junho 2020. URL : http://journals.openedition.org/espacoeconomia/1323 ; DOI : https://doi.org/10.4000/espacoeconomia.1323

Este documento foi criado de forma automática no dia 13 junho 2020.

(c) NUPEE 


\section{Observações acerca da reestruturação urbana na Zona Portuária do Rio de Janeiro}

Remarks on urban restructuring in Rio de Janeiro's dockland

Observaciones sobre la reestructuración urbana en la zona portuaria de Río de Janeiro

Remarques sur la restructuration urbaine de la zone portuaire à Rio de Janeiro

Gabriel Silva de Araujo Teixeira

\section{NOTA DO AUTOR}

Trabalho de campo realizado na Zona Portuária do Rio de Janeiro, no dia 7 de Outubro de 2014

1 A Zona Portuária do Rio de Janeiro está em obras. Muito além da bastante anunciada demolição da Perimetral, o que se observa é o erguimento de imensos empreendimentos imobiliários entre os galpões velhos e o surgimento de aparatos urbanísticos de padrão internacional. No trabalho de campo foi possível perceber essa nova configuração paisagística que aos poucos renova a degradada área central da cidade.

Difícil compreender ainda suas feições arquitetônicas por estarem em processo de construção, o que se sabe é que está em andamento um projeto novo de cidade, elaborado por uma parceria público-privada, entre a Prefeitura do Rio e o Consórcio Porto Novo (formado pela OAS, Odebrecht e Carioca Engenharia). Porém, é possível apreender o que se passa na Zona Portuária se nos debruçarmos sobre os projetos em andamento, analisados no trabalho de campo, e sobre alguns pressupostos teóricos. A predominância dos empreendimentos imobiliários é evidente nessa parte do Rio de 
Janeiro e tal processo de "hegemonia imobiliária" é explicado por Paulo Cesar Xavier Pereira, quando o autor trata da cidade contemporânea. Segundo ele

"O entendimento a ser retido é de que há uma dissolução do urbano, no sentido de que o urbano como lócus da reprodução da força de trabalho tende a se dissolver. E o processo urbano a serviço da reprodução da força de trabalho, com destaque para as condições gerais e públicas, perde relevância para definir o crescimento da cidade e os rumos de sua expansão. O imobiliário (mercantil) é que, sob a hegemonia da forma de produção para o mercado, toma a direção do processo urbano e da construção da cidade" (Pereira, 2011)

3 Portanto, o processo imobiliário que se desenvolve na Zona Portuária estabelece uma nova perspectiva sobre a criação do urbano. Quando se analisa o tamanho dos empreendimentos e o perfil do agentes imobiliários que estão em ação, percebe-se que será uma cidade construída para poucos. A quantidade diminuta de habitações em detrimento dos quartos de hotel pode evidenciar os planos de incluir essa parte da cidade num circuito a nível internacional, com a presença de rede hoteleiras mundialmente conhecidas, como a Rede Ibis, a Novotel e a Holiday Inn. Além da francesa operadora hoteleira Accor Hotels e da britânica InterContinental Hotels Group.

4 Os agentes que atuam na região tem implantado um padrão de urbanização que difere do anterior abandono da área por parte dos agentes públicos. Ao contrário da intensificação das ações urbanísticas públicas, passa-se para a iniciativa privada a preocupação com a manutenção do local, configurando a privatização do urbano. Ao contrário do que se pode imaginar, a urbanização privada não está restrita aos condomínios murados, se utilizam de outros meios para subordinar determinado local ao controle de um grupo privado.

Sobre as condições da urbanização privada sem muros, Vidal-Koppmann aponta:

- La propuesta de desarrollo urbano de la totalidad del conjunto que es encerada por una empresa y se financia con capitales privados

- La gestión de los servicios que es realizada de forma autónoma y privada

- Los sistemas de seguridad y vigilancia que tambíen son contratados a empresas

privadas (Koppmann,2011)

6 No caso do Rio de Janeiro, foram substituídos os serviços de limpeza da estatal COMLURB por empresas terceirizadas, contratadas e gerenciadas pelo Consórcio Porto Novo. As câmeras espalhadas pelo local também são administradas pelo Consórcio. Ou seja, uma gama de demandas urbanas de interesse comum sendo geridas pela iniciativa privada, que assim tem suas próprias demandas atendidas com mais facilidade.

7 Aqui serão abordados três desses empreendimentos que dão o tom da construção dessa nova cidade. Trata-se do Hotel Praia Formosa, do Porto Atlantico Bunisses Square e o Porto Vida Residencial (vila dos árbitros). O que esses três investimentos tem em comum é a Odebrecht (quadro 1), empresa que atua fortemente na região como construtora. 
Quadro 1 - empreendimentos em construção na área portuária do Rio de Janeiro

\begin{tabular}{|c|c|c|c|}
\hline & $\begin{array}{c}\text { Hotel Praia Formos a } \\
\text { (Holiday Inn) }\end{array}$ & PortoVida (vila dos árbitros) & $\begin{array}{c}\text { Porto Atlantico (Ibis e } \\
\text { Novotel) }\end{array}$ \\
\hline \multicolumn{4}{|l|}{ Proprie tária } \\
\hline & $\begin{array}{c}\text { Odebrecht Realizą̧ões } \\
\text { Imobiliárias }\end{array}$ & $\begin{array}{c}\text { Porto } 2016 \text { Empreend imentos } \\
\text { Imobiliários }\end{array}$ & \\
\hline Construtora & $\begin{array}{c}\text { Odebrecht Realizações } \\
\text { Imobiliárias }\end{array}$ & & $\begin{array}{c}\text { Od eb recht Realizações } \\
\text { Imo biliárias }\end{array}$ \\
\hline Inob iliária & & Bras il Brokers & $\begin{array}{l}\text { Performance } \\
\text { Empreend imentos } \\
\text { imobiliários }\end{array}$ \\
\hline Unid ad es & $\begin{array}{l}594 \text { quartos } ; 33 \\
\text { pavimentos }\end{array}$ & 1.333 unidades; 33 lojas; 7 torres & 830 unidades \\
\hline Financiamento & Itaí & & Brades co \\
\hline
\end{tabular}

Fonte: elaboração do autor, 2014

8 O Hotel Praia Formosa, o mais perceptível na paisagem, se apropriou do nome da antiga estação de trem que funcionava no local. Até o ano de 2003 o terreno era utilizado como pátio de manobras dos trens da Ferrovia Centro-Atlântica. O que surge no terreno agora é um grande edifício, planejado para ter 33 pavimentos. O investimento é da rede hoteleira Holiday Inn, que pertence a operadora hoteleira britânica InterContinental Hotels Group, considerada a maior em número de quartos no mundo (World Ranking 2013 Of Hotel Groups). Será o primeiro da rede no Rio de Janeiro, embora já operem em mais de 10 capitais brasileiras. Segundo o Parecer Técnico encomendado pela própria Holiday Inn, o investimento escolheu como local "a emergente região do Porto Maravilha", tendo como "força motriz" os Jogos Olímpicos de 2016. Ao lado da construção, dentro do mesmo terreno, se localiza o Centro de Reciclagem de Resíduos das Obras do Porto Maravilha, proveniente de uma resolução de lei do CONAMA ( $\left.n^{\circ} 307 / 2002\right)$ que estabelece diretrizes sobre a gestão dos resíduos da construção civil.

9 Também no mesmo terreno está em obra o Porto Vida Residencial, serão 1.333 unidades mais 33 lojas, distribuídos em 7 torres. 0 padrão de construção é bem diferente do empreendimento vizinho, com materiais aparentemente menos custosos e menos tecnologia. $O$ ritmo da obra também é diferente. Embora estejam erguidas as fundações e parte das estruturas, a obra parece abandonada. A obra pertence ao Porto 2016 Empreendimentos Imobiliários, que pertence à Concessionária Porto Novo. 0 projeto original previa medidas inovadoras para um conjunto habitacional, com um espaço verde interno aberto ao público, de maneira que permitiria a circulação da cidade. No entanto, modificações no projeto colocam no lugar uma área de lazer fechada aos moradores. O presidente do IAB, em entrevista ao jornal O Globo, expressa sua preocupação com o rumo do projeto e possível futuro da Zona Portuária: "É uma pena que o mercado esteja, de certo modo, impondo os valores que já vem trazendo desde sempre (...) Para que o Porto dê certo, é importantíssimo que seja um bairro de uso múltiplo, com moradia, pequenos comércios, lazer, prédios corporativos.".

O Porto Vida Residencial, por ser residencial não conta com os investimentos de capital internacional de redes hoteleiras, como seu vizinho. Isso pode explicar a grande diferença no padrão de obras.

Outra obra expressiva na região é o Porto Atlantico Bunisses Square, planejado para ser um complexo de edifícios, contendo hotéis, centros de convenções, lojas e salas 
corporativas. O empreendimento vai ocupar dois quarteirões e vai contar com cinco edifícios, com andares de até $2.024 \mathrm{~m}^{2}$. Segundo o site da Odebrecht Realizações todas as 830 unidades já foram vendidas. No momento, foi possível observar durante o campo, a estrutura de um dos edifícios.

Diante disso, dois aspectos devem ser ressaltados sobre a modificação urbana da Zona Portuária:

I) atrai medidas urbanísticas da Prefeitura até então distantes do local;

II) modificam os modos de usar aquele espaço e as funções para quais era destinado.

o primeiro aspecto se refere ao casamento perfeito entre empreendimentos privados e inciativas públicas, por mais que algumas dessas iniciativas, como vimos anteriormente, sejam apenas medidas de transferência de responsabilidade (para o setor privado). Ao redor dos terrenos separados para os investimentos imobiliários, surge um novo padrão de calçadas e iluminação implantados pela Prefeitura. Calçadas que insinuam a arborização das vias urbanas e que contêm um padrão de divisão em três faixas: faixa de serviço (para alocar o mobiliário urbano), faixa livre (de cor vermelha, para livre circulação de pedestres) e faixa de acesso (colada a porta dos imóveis, para receber o mobiliário móvel). E uma iluminação com lâmpadas LED e fiação totalmente subterrânea, contando também com um aparato de vigilância, com aparentes câmeras em alguns postes. Além do traçado do VLT, já em obras, que serpenteia entre os terrenos destinados aos empreendimentos imobiliários. A construção do VLT foi possibilitada pelo Programa de Aceleração do Crescimento (PAC), através do Ministério das Cidades, para permitir o acesso da população ao Centro. Cabe questionar qual a lógica de implantar um sistema de transporte numa área que até ontem predominavam galpões antigos e abandonados e agora erguem-se hotéis de grande porte.

16 Já o segundo aspecto, é possível perceber no destino dos galpões e armazéns presentes na Zona Portuária. Alguns já derrubados para dar lugar às novas construções, outros ainda em seu estado degradado, servindo como reserva de valor e outros sendo revitalizados. A Avenida Rodrigues Alves é exemplo desse último. Numa breve passagem pela parte em obra dessa avenida, observa-se alguns armazéns já revitalizados. O Festival Internacional de Cinema do Rio, por exemplo, tem sua sede este ano no antigo armazém 6, hoje nomeado Armazém da Utopia, destinado a atividades culturais. Toda a avenida por onde antes passava a Perimetral vai dar lugar a um Boulevard, que levará outros usos aos galpões e armazéns da área, desencadeando um processo de coesão espacial, ou seja, atraindo serviços que se complementam.

17 Contudo, o ritmo dessas construções é pouco perceptível para o transeunte que cotidianamente passa pela área. Isso porque não se ouve barulho por ali, além dos já habituais sons de um centro urbano. Essas novas edificações vão brotando na paisagem sorrateiramente. No entanto, assim se evidencia um tipo diferente de aparelhamento técnico que dispõem essas construtoras e investidores. Os trabalhadores são escassos nos grandes terrenos em construção.

Outro local que está sendo alvo de transformações de seus usos é o Morro da Conceição. O morro, que historicamente era ocupado por parcelas mais pobres da população, tem sentido o impacto de ver-se inserido nos circuitos turísticos-culturais. Durante o campo foi possível visualizar a alteração/revitalização de algumas fachadas, também o surgimento de ateliers ocupando antigas residências e bares que fogem ao padrão dos 
tradicionais do morro. $\mathrm{O}$ aluguel no local atualmente alcança dois mil reais mensais. A exploração desse circuito tem sido fomentada pela Concessionária Porto Novo (ligada a todas as obras da região), através do também recente Museu de Arte do Rio (MAR), que alimenta projetos como o promovido em 2012, "O morro e o mar", fazendo visitas guiadas aos ateliers do Morro da Conceição.

Pautada por leis flexíveis e pela falta de planejamento em conjunto com a população, o projeto Porto Maravilha impõe a cidade de exceção (Vainer,2013). Em nome dos discurso de revitalização da cidade, e pela promessa de tornar o local apto para ser apropriado pelos citadinos, a Zona Portuária é invadida por redes hoteleiras internacionais, que nada se preocupam com a condição de existência da cidade como um todo. Implantam a "democracia direta do capital", e atuam na cidade interpretando-a como a cidade-empresa, onde a eficiência economia é a lei, que tem por evidente sintoma a despolitização do espaço.

O entusiasmo festivo em relação aos Jogos Olímpicos contribui para o ânimo em relação às alterações que vem sofrendo a Zona Portuária. No entanto, o preço de um Centro renovado é ver entregue aos investidores a decisão sobre o uso dos terrenos e consequentemente o desmantelamento do interesse comum em prol dos objetivos de um consórcio de construtoras e imobiliárias. O Porto Maravilha vive um momento de condição político-econômica segura para ser entregue aos interesses de um grupo que encara o espaço como lugar de acumulo financeiro. A cidade do Rio de Janeiro vê surgir grandes edifícios novos, mas o alicerce que se oculta no discurso da renovação da cidade é, na verdade, a renovação de um arranjo de poder que legitima a negação da cidade.

\section{BIBLIOGRAFIA}

BRAGA, Gilberto; HERINGER, Marcos. Parecer Técnico, análise de viabilidade econômica do empreendimento Holiday Inn. Disponível em: http://www.holidayinnportomaravilha.com.br/ pdf/viabilidade.pdf. Acesso em: 10 Out 2014.

PEREIRA, Paulo Cesar Xavier. Agentes imobiliários e reestruturação: interesses e conflitos na construção da cidade contemporânea. In: Pereira, Paulo Cesar Xavier (Org.). Negócios imobiliários e transformações sócio-territoriais em cidades da America Latina. São Paulo: FAUUSP, 2011, p. 23-31

VAINER, Carlos. Cidade de Exceção: Reflexões a partir do Rio de Janeiro. In: Carlos Machado; Caio Floriano dos Santos; Claudionor Ferreira Araújo; Wagner Valente dos Passos. (Org.). Conflitos Ambientais e Urbano: Debate, Lutas e Desafios. 1ed.Porto Alegre: Evangraf, 2013

VIDAL-KOPPMANN, Sonia. Urbanizaciones cerradas em la Región Metropolitana de Buenos Aires: articulación socioespacial de actores públicos y privados. In: Pereira, Paulo Cesar Xavier (Org.). Negócios imobiliários e transformações sócio-territoriais em cidades da America Latina. São Paulo: FAUUSP, 2011, p.113-133 
TAVARES, Karine. O primeiro residencial do Porto. O Globo, Rio de Janeiro, Jun 2013. Disponível em: < http://oglobo.globo.com/economia/imoveis/o-primeiro-residencial-do-porto-8573697>

World Ranking 2013 of Hotel Groups And Brands. Disponível em: http://www.hospitalitynet.org/ news/4060119.html . Acesso em: 11 Out 2014

\section{RESUMOS}

As obras de reestruturação urbana que se realizam na zona portuária do Rio de Janeiro suscitam questões sobre os processos e interesses presentes na concessão de direitos de construção, conferido pela Administração Municipal. Nossa pesquisa busca investigar os agentes envolvidos e o novo padrão urbanístico que está sendo implantado na área.

Urban restructuring constructions carried out in Rio de Janeiro's dockland raise issues on procedures and interests at stake concerning building permits granted by the city's administration. This research aims to examine the agents involved in this process as well as the urban patterns implemented in that specific area.

Las obras de reestructuración urbana llevando a cabo en la zona portuaria de Río de Janeiro plantean algunas preguntas sobre los procesos y los intereses presentes en la concesión de derechos del construcción, conferidos por la Administración Municipal. Nuestra investigación pretende investigar los agentes implicados y el nuevo patrón urbano que está siendo desplegado en la zona.

L'oeuvre de restructuration urbaine réalisée à la zone portuaire de la ville de Rio de Janeiro suscite des questions sur les processus et les intérêts inscrits dans la concession des droits de construction octroyées par la Municipalité. On vise à reconnaître les acteurs liés à ce projet et le nouveau modèle urbanistique mis en oeuvre.

\section{ÍNDICE}

Mots-clés: restructuration urbaine, agents immobiliers, ville de Rio de Janeiro, le marché de l'immobilier, la zone de port de Rio de Janeiro

Palavras-chave: agentes imobiliários, cidade do Rio de Janeiro, reestruturação urbana, mercado imobiliário, zona portuária do Rio de Janeiro

Palabras claves: agentes inmobiliarios, la ciudad de Rio de Janeiro, renovación urbana, mercado de la vivienda, la zona del puerto de Rio de Janeiro

Keywords: real estate agents, city of Rio de Janeiro, urban restructuring, the real estate market, the port zone of Rio de Janeiro

\section{AUTOR}

\section{GABRIEL SILVA DE ARAUJO TEIXEIRA}

Granduando em Geografia na Universidade do Estado do Rio de Janeiro, Bolsista de Iniciação científica com bolsa do CNPq. gabrielgeouerj@gmail.com 